\title{
A Method for Steel Ladle Lining Optimization Applying Thermomechanical Modeling and Taguchi Approaches
}

\author{
AIDONG HOU, ${ }^{1}$ SHENGLI JIN $(1),{ }^{1,2}$ HARALD HARMUTH, ${ }^{1}$ and \\ DIETMAR GRUBER ${ }^{1}$ \\ 1.-Montanuniversitaet, Leoben 8700, Austria. 2.-e-mail: shengli.jin@unileoben.ac.at
}

\begin{abstract}
Successful lining concept design can avoid the premature wear of refractory linings, allow for more economically efficient configuration of refractories, and improve the efficiency of high-temperature processes and save energy. The present paper introduces the Taguchi method combining finite element (FE) modeling for the lining optimization of a steel ladle from thermal and thermomechanical viewpoints. An orthogonal array was applied to design lining configurations for FE simulations. Analysis of variance and signal-to-noise ratio were used to quantitatively assess the impact of factors on thermal and thermomechanical responses. As a result, two optimal lining concepts using commercially available materials were proposed, which showed a substantial decrease in heat loss through the steel shell and thermomechanical load at the hot face of the working lining. The combined application of FE thermomechanical modeling and Taguchi approaches facilitates the selection of proper commercial materials and thicknesses of linings for the given process conditions.
\end{abstract}

\section{List of symbols}

Total number of factors

Total number of levels

Total number of runs

Index referring to factor

Index referring to level

Index referring to observation

Number of runs at the $i$ th level of a factor

Strength of an orthogonal table

Value of $j$ th observation at the $i$ th level of a factor

Mean of observations at $i$ th level of a factor

Mean of all observations

Total sum of squares

Sum of squares for each factor

Sum of squares of deviation

Mean square for each factor

Mean square of deviation

Degrees of freedom of each factor

Degrees of freedom of deviation

Ratio of mean square for each factor to that of the deviation

\begin{abstract}
$\alpha$
is true

C Contribution in percentage
\end{abstract}

\section{INTRODUCTION}

Steel ladles, composed of refractories and steel construction components, act as transportation vessels and refining units for the steel melt. Refractory linings insulate the steel shell from the steel melt, and thus reduce the heat loss from the steel shell. A well-lined steel ladle offers efficient temperature control of the steel melt and is beneficial to the steel quality and productivity. ${ }^{1-4}$

The thermomechanical behavior of steel ladle linings has been extensively studied with regard to relevant process conditions, material properties, and lining configurations by means of finite 
element (FE) methods. ${ }^{5-12}$ These studies show that ladles without preheating experience higher compressive stresses at the hot face of the working lining, which may lead to a compressive failure, ${ }^{5-7}$ by preheating for preferably $15-20 \mathrm{~h}$, these stresses can be reduced. ${ }^{8}$ In addition, an increased ladle preheating temperature can reduce the temperature drop of the steel melt and the temperature gradient of ladle linings, mitigate the thermal shock damage of lining materials, and thus extend the service life of the steel ladle. ${ }^{9}$ The effects of insulation in a steel ladle were evaluated from the thermal and thermomechanical points of view. A compliant insulation layer led to a decrease in heat loss and thermomechanical loads at the hot face of the working lining. ${ }^{6}$ The possible application of an insulating material with rather low thermal conductivity was evaluated using FE simulations of a steel ladle. ${ }^{12}$

In contrast to the post-mortem study of an existing vessel lining concept, an a priori method was proposed for the design of lining concepts before putting them into practice with a case study of a channel induction furnace lined with monoliths. ${ }^{13-15}$ An orthogonal array was utilized to systematically design the lining concepts, and the FE method was applied to calculate the temperatures and stresses of the furnace linings. Afterwards, an analysis of the main effects was performed to rank the impact of individual factors and determine the optimal value of each factor. The optimized lining concept was compared with the reference case from the thermal and thermomechanical points of view, taking into account irreversible behavior of the working lining material. The studies established a feasible and efficient methodology for optimization of lining concepts using a considerable number of variables of vessels made of monolithic linings.

The present paper extends the above-mentioned method for the lining concept optimization of vessels with brick working linings. A case study of a steel ladle considers the variations of material properties and lining geometry. Moreover, advanced analysis methods, i.e., analysis of variance (ANOVA) and signal-to-noise $(S / N)$ ratio according to the Taguchi method, were applied to assess the contribution and optimal level of significant factors.

\section{TAGUCHI METHOD}

As an improved method of design of experiments, the Taguchi method, developed by G. Taguchi in the late $1940 \mathrm{~s}$, is widely used in manufacturing processes, ${ }^{16,17}$ material design and development, ${ }^{18}$ and geometry design. ${ }^{19} \mathrm{~A}$ routine set of tools in the Taguchi method includes orthogonal arrays, ANOVA, and the $S / N$ ratio. Their performances are briefly introduced in the following subsections.

\section{Orthogonal Arrays}

Orthogonal arrays are highly fractional factorial designs and yield a minimum number of experimental runs. An orthogonal array with the same number of levels $l$ for all $m$ factors is designated with the sign of $L_{N}\left(l^{m}\right)$, where $N$ is the total number of experiment runs, and $L$ represents Latin squares. When the level size of certain factors is different, for instance, $m_{1}$ factors have $l_{1}$ levels and $m_{2}$ factors have $l_{2}$ levels, then it is denoted $L_{N}\left(l_{1}^{m_{1}} \times l_{2}^{m_{2}}\right)$. The former is called a pure orthogonal array and the latter one a mixed-level orthogonal array. In one orthogonal array with a strength of $t$, the occurrence of each level of one factor in each column is equal and the combination of levels in $t$ factors occurs equally. Additional details are described in other works. ${ }^{20,21}$

\section{Analysis of Variance (ANOVA) ${ }^{22}$}

ANOVA is a statistical method used to quantitatively assess the significance of factors to responses and their confidence. Five values are used to assess a factor's significance: the sum of squares, the degrees of freedom, the mean square, the $F$ value, and the percent contribution of the factor.

The total sum of squares (subscript T) measures the overall variability of data and is calculated using all of the observed values for different factors

$$
\mathrm{SS}_{\mathrm{T}}=\sum_{i=1}^{l} \sum_{j=1}^{n_{i}}\left(y_{i j}-\bar{y}_{t}\right)^{2},
$$

where $l$ is the number of levels, $n_{i}$ is the number of runs at the $i$ th level, $y_{i j}$ is the value of $j$ th observation at $i$ th level, and $\bar{y}_{t}$ is the mean of all observations.

The sum of squares for each factor (subscript $f$ ) is given by

$$
\mathrm{SS}_{\mathrm{f}}=n_{i} \sum_{i=1}^{l}\left(\bar{y}_{i}-\bar{y}_{t}\right)^{2},
$$

where $\bar{y}_{i}$ is the mean of observations at the $i$ th level.

Subtracting the sum of $\mathrm{SS}_{\mathrm{f}}$ of all factors from $\mathrm{SS}_{\mathrm{T}}$ leads to

$$
\mathrm{SS}_{\mathrm{D}}=\mathrm{SS}_{\mathrm{T}}-\sum_{k=1}^{m} \mathrm{SS}_{\mathrm{f}}(k),
$$

where $m$ is the total number of factors and $k$ is the index referring to a factor. $\mathrm{SS}_{\mathrm{D}}$ is the sum of squares of the deviation (subscript D).

The degrees of freedom of each factor, $\mathrm{DoF}_{\mathrm{f}}$, is equal to $(l-1)$ when the number of its level is $l$.

The mean square for each factor (subscript $f$ ) is

$$
\mathrm{MS}_{\mathrm{f}}=\mathrm{SS}_{\mathrm{f}} / \mathrm{DoF}_{\mathrm{f}}
$$

and the mean square of deviation is 
(a)

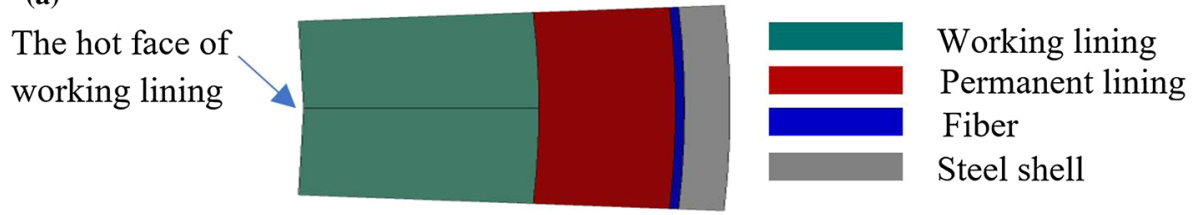

(b)
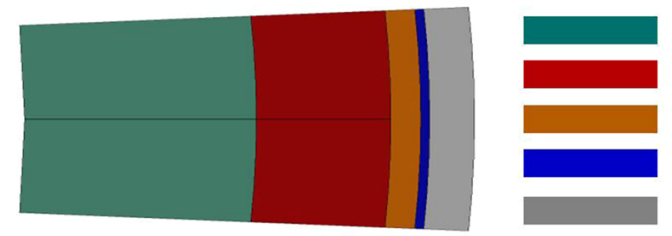

Working lining

Permanent lining

Insulation

Fiber

Steel shell

Fig. 1. (a) Two-dimensional model of the reference steel ladle case; (b) two-dimensional model of the steel ladle for the lining concept optimization study.

Table I. Ladle component thickness and material properties of the reference case

\begin{tabular}{|c|c|c|c|c|}
\hline Linings & $\begin{array}{l}\text { Thickness } \\
\text { (mm) }\end{array}$ & $\begin{array}{l}\text { Thermal conductivity } \\
\qquad\left(\mathbf{W} \mathbf{~ m}^{-1} \mathbf{K}^{-1}\right)\end{array}$ & $\begin{array}{l}\text { Young's modulus } \\
\text { (GPa) }\end{array}$ & $\begin{array}{l}\text { Thermal expansion } \\
\text { coefficient }\left(10^{-6} \mathrm{~K}^{-1}\right)\end{array}$ \\
\hline Working lining & 155 & 8.5 & 60 & 11.5 \\
\hline Permanent lining & 90 & 2.2 & 45 & 6.0 \\
\hline Fiber & 6 & 0.17 & 0.3 & 9.0 \\
\hline Steel shell & 30 & 50 & 210 & 12.0 \\
\hline
\end{tabular}

$$
\mathrm{MS}_{\mathrm{D}}=\mathrm{SS}_{\mathrm{D}} / \mathrm{DoF}_{\mathrm{D}}
$$

where $\mathrm{DoF}_{\mathrm{D}}$ is the degrees of freedom of deviation (subscript D) given by

$$
\mathrm{DoF}_{\mathrm{D}}=N-1-\sum_{k=1}^{m}\left(l_{k}-1\right)
$$

where $N$ is the total number of runs.

The $F$-statistic value of each factor is calculated using the equation below,

$$
F=\mathrm{MS}_{\mathrm{f}} / \mathrm{MS}_{\mathrm{D}}
$$

Afterwards, the obtained $F$ value can be compared with the corresponding critical value, $F_{\alpha}\left(\mathrm{DoF}_{\mathrm{f}}\right.$, $\left.\mathrm{DoF}_{\mathrm{D}}\right)$ at the $(1-\alpha)$ confidence level in the $F$ distribution table. ${ }^{22}$ If the calculated $F$ value is larger than the critical value, the probability of correctly accepting the null hypothesis is $(1-\alpha)$. The percent contribution of each factor is defined as

$$
C=\mathrm{SS}_{\mathrm{f}} /\left(\mathrm{SS}_{\mathrm{T}}-\mathrm{SS}_{\mathrm{D}}\right) \times 100 \% .
$$

\section{Signal-to-Noise $(S / N)$ Ratio $^{20}$}

The $S / N$ ratio is extensively used as a quality index, rather than being merely associated with the signal and noise. Three $S / N$ ratio representations are shown in Eqs. 9-11: smaller-the-better, nominal-the-best, and larger-the-better. For all representations, a higher $S / N$ ratio is desirable. In the present work, the smaller-the-better equation is used to evaluate the thermal and thermomechanical responses because the equation treats the smallest value of responses as the best quality.

$$
\text { Smaller - the - better: } S / N=-10 \log \left(\frac{1}{n_{i}} \sum_{j=1}^{n_{i}} y_{i j}^{2}\right)
$$

Nominal - the - best : $S / N=-10 \log \left(\frac{1}{n_{i}} \sum_{j=1}^{n_{i}}\left(y_{i j}-\bar{y}_{i}\right)^{2}\right)$,

$$
\text { Larger - the - better }: S / N=-10 \log \left(\frac{1}{n_{i}} \sum_{j=1}^{n_{i}} \frac{1}{y_{i j}^{2}}\right) \text {. }
$$

Here $n_{i}$ is the number of runs at the $i$ th level, $y_{i j}$ is the value of the $j$ th observation at the $i$ th level, and $\bar{y}_{i}$ is the mean number of observations at the $i$ th level of a factor.

\section{FINITE ELEMENT MODEL AND PARAMETER DESIGN}

A steel ladle of voestalpine was the object used for lining concept optimization. Figure 1a depicts the simplified two-dimensional model representing a 
Table II. Variations in ladle component thicknesses and material properties

\begin{tabular}{|c|c|c|c|c|c|}
\hline \multirow[b]{2}{*}{ Impact factors } & \multicolumn{4}{|c|}{ Levels } & \multirow[b]{2}{*}{ Label of factors } \\
\hline & $\mathbf{1}$ & 2 & 3 & 4 & \\
\hline \multicolumn{6}{|l|}{ Thickness (mm) } \\
\hline Working lining & 250 & 200 & 155 & 50 & $A$ \\
\hline Permanent lining & 130 & 110 & 90 & 65 & $B$ \\
\hline Insulation lining & 37.5 & 25 & 15 & 6 & $C$ \\
\hline Steel shell & 30 & 20 & & & $J$ \\
\hline \multicolumn{6}{|l|}{$\begin{array}{l}\text { Thermal conductivity } \\
\left(\mathrm{W} \mathrm{m} \mathrm{m}^{-1} \mathrm{~K}^{-1}\right)\end{array}$} \\
\hline Working lining & 9 & 8.5 & 7 & 3 & $D$ \\
\hline Permanent lining & 9 & 5 & 3 & 2.2 & $E$ \\
\hline Insulation lining & 1.35 & 0.5 & 0.35 & 0.15 & $F$ \\
\hline \multicolumn{6}{|c|}{ Young's modulus (GPa) } \\
\hline Working lining & 100 & 80 & 60 & 40 & $G$ \\
\hline Permanent lining & 90 & 45 & 30 & 10 & $H$ \\
\hline Insulation lining & 35 & 4 & 3 & 0.17 & $I$ \\
\hline
\end{tabular}

horizontal cut through the slag-line position in the upper part of the steel ladle. The model consists of a two half-brick working lining, a monolithic permanent lining, a fiber board, and a steel shell. The radial expansion allowance between two bricks of the working lining was $0.4 \mathrm{~mm}$. The thicknesses and material properties of different linings are listed in Table I. The thermal conductivity and Young's modulus of materials were defined as being temperature-independent.

Another two-dimensional model including an additional insulating lining was established for the lining concept optimization study, as shown in Fig. 1b. In this model, the permanent lining was made of bricks. The radial expansion allowance between two bricks was $0.4 \mathrm{~mm}$. The variations of lining thickness, thermal conductivity, and Young's modulus of materials for the respective linings are shown in Table II. It is worth noting that the material property variations in Table II are those of commercial products and ranked in a descending order. The thermal conductivity and Young's modulus of the materials were also defined as being temperature-independent. The candidate refractory materials for each lining were assumed to possess the same coefficient of thermal expansion $\left(1.2 \times 10^{-6} \mathrm{~K}^{-1}\right)$ in the present linear elastic modeling and optimization procedure. A consideration of different coefficients of thermal expansion is necessary if the materials for one lining show a significant deviation in the coefficients of thermal expansion or if the irreversible behavior of refractories is taken into account. Finally, in total, ten factors were of interest in this research, nine of which had four levels, together with the thickness of the steel shell, which had two levels. A mixed-level orthogonal array $L_{32}\left(4^{9} \times 2^{1}\right)$ according to the Taguchi method was applied.
The finite element modeling of the steel ladle with an elastic material behavior was performed using the commercial software, ABAQUS. The process included preheating of the hot face of the working lining for $20 \mathrm{~h}$ to $1100^{\circ} \mathrm{C}$ and a subsequent thermal shock caused by tapping the steel melt with a temperature of $1600^{\circ} \mathrm{C}$ into the ladle. After the refining period of $95 \mathrm{~min}$, a 50-min idle period followed. Displacement of linings was allowed in the radial direction and constrained in the circumferential direction. The heat transfer between the interfaces of linings, the liquid melt and hot face of the working lining, and the cold end of the steel shell and atmosphere was considered.

\section{RESULTS}

\section{Contribution of Impact Factors to the Thermal and Thermomechanical Responses}

The present study aims to decrease the heat loss from the steel shell and the thermomechanical loads on the working lining and steel shell. Thus, the chosen responses were the temperature at the cold end of the steel shell, the maximum tensile stress at the steel shell, and the maximum compressive stress at the hot face of the working lining. ANOVA was applied to quantitatively investigate the significance of impact factors, according to the equations in "Analysis of Variance (ANOVA)[22]" section.

The results for the thermal response are exemplarily shown in Table III. The top four significant impact factors to the temperature at the cold end of the steel shell were the thickness of the working lining $(A)$, the thermal conductivity of the insulation material $(F)$, the thickness of insulation material $(C)$, and the thermal conductivity of the working lining material $(D)$, in descending order. Their individual confidence levels were all higher than $90 \%$ and, when combined, they contributed $89 \%$ of 
Table III. ANOVA results of the temperature at the cold end of the steel shell

\begin{tabular}{|c|c|c|c|c|c|c|}
\hline Factor & $\mathbf{D o F}_{\mathbf{f}}$ & $\underline{\mathbf{S S}_{\mathbf{f}}\left({ }^{\circ} \mathbf{C}^{2}\right)}$ & $\mathbf{M S}_{\mathbf{f}}\left({ }^{\circ} \mathbf{C}^{\mathbf{2}}\right)$ & $F-V$ value & Confidence (\%) & Contribution (\%) \\
\hline$A$ & 3 & 59,596 & $19,865.4$ & 14.39 & 95 & 31.27 \\
\hline$B$ & 3 & 8473 & 2824.4 & 2.05 & & 4.45 \\
\hline$C$ & 3 & 37,878 & $12,625.9$ & 9.15 & 90 & 19.88 \\
\hline$D$ & 3 & 32,659 & $10,886.4$ & 7.89 & 90 & 17.14 \\
\hline$E$ & 3 & 10,464 & 3488 & 2.53 & & 5.49 \\
\hline$F$ & 3 & 38,746 & $12,915.3$ & 9.36 & 95 & 20.33 \\
\hline$G$ & 3 & 1958 & 652.7 & 0.47 & & 1.03 \\
\hline$H$ & 3 & 261 & 87 & 0.06 & & 0.14 \\
\hline$I$ & 3 & 407 & 135.8 & 0.1 & & 0.21 \\
\hline$J$ & 1 & 121 & 121.1 & 0.09 & & 0.06 \\
\hline
\end{tabular}

$\mathrm{SS}_{\mathrm{T}}=194,705, \mathrm{SS}_{\mathrm{D}}=4142, \mathrm{MS}_{\mathrm{D}}=1380.6, \mathrm{DoF}_{\mathrm{D}}=3$.

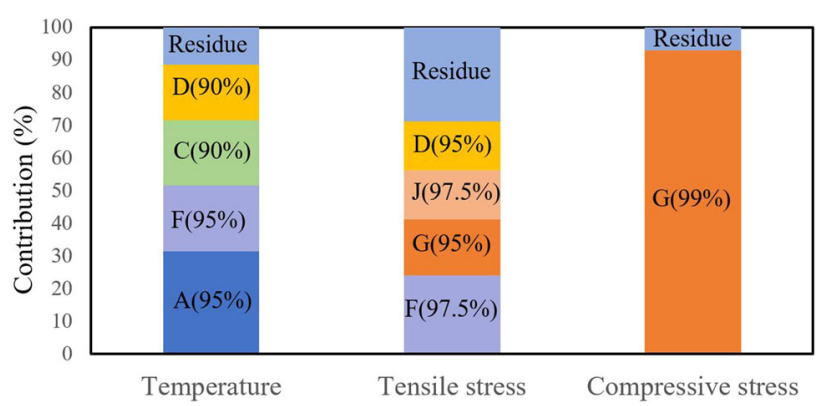

Fig. 2. Contribution and confidence levels (in parentheses) of factors for thermal and thermomechanical responses.

the thermal response. Therefore, further lining concept design will focus primarily on these four impact factors.

The same analysis procedure was carried out for thermomechanical responses. The summarized results with respect to the thermal and thermomechanical responses are shown in Fig. 2. In the case of tensile stress at the steel shell, the thermal conductivity of the insulation material $(F)$ contributed the largest portion among the impact factors and is followed by the Young's modulus of the working lining material $(G)$, the thickness of the steel shell $(J)$, and the thermal conductivity of the working lining material $(D)$. The first four significant impact factors each had confidence levels greater than $95 \%$ and contributed $71 \%$ of the tensile stress at the steel shell. The Young's modulus of the working lining $(G)$ had an overwhelming influence on the compressive stress at the hot face of the working lining, with a $93 \%$ contribution.

\section{Optimization Study of Factor Level}

The $S / N$ ratios of the thermal and thermomechanical responses were calculated with respect to the factor level and are shown in Fig. 3 and the supplementary figures. For each factor, the level showing the largest $S / N$ ratio will be considered the optimal one. Figure 3 shows that the optimal $S / N$ ratios for the temperature at the cold end of the steel shell were A1B2C1D4E4F4G1H1I3J1. The optimal $S / N$ ratios for the maximum tensile stress at the steel shell and for the maximum compressive stress at the hot face of the working lining were A4B4C4D4E2F1G4H4I4J1 and A4B2C2D3E1F3G4H1I1J2, respectively (see "supplementary figures S1 and S2").

Table IV summarizes the optimal levels for each response with the contribution of each factor according to the ANOVA and $S / N$ ratio studies. In the case of the compressive stress at the hot face of the working lining, the Young's modulus of the working lining $(G)$ dominated the contribution, whereas the smallest Young's modulus of the working lining is preferable. For the tensile stress and temperature responses at the cold end of the steel shell, the factors can be classified into two groups: one with the same optimal level for both responses, and the other with a contradictory trend. The decision can be easily made for the first group of factors $(D, I, J)$. For the second group $(A, B, C, E, F, H)$, the quantitative ANOVA results facilitate the further choice of levels. That is to say, the optimal level of one factor showing a higher contribution to one response (temperature or tensile stress) is preferable. For instance, the working lining and insulation lining thickness ( $A$ and $C$ ) occupied $31 \%$ and $20 \%$ contribution to the steel shell temperature, respectively, whilst only $5 \%$ and $7 \%$ to the tensile stress of the steel shell. Therefore, the application of a thicker lining is considered to take priority. The thickness of the permanent lining $(B)$, the thermal conductivity $(E)$, and the Young's modulus $(H)$ of the permanent lining did not play a significant role in either responses. Factor $\mathrm{F}$ had a rather equal contribution to the two responses and thus a compromise will be made, for example, a moderate insulation effect.

The analysis results according to the Taguchi method were further compared with those from the standard analysis of the mean value method. The mean value method indicates the optimal level and 


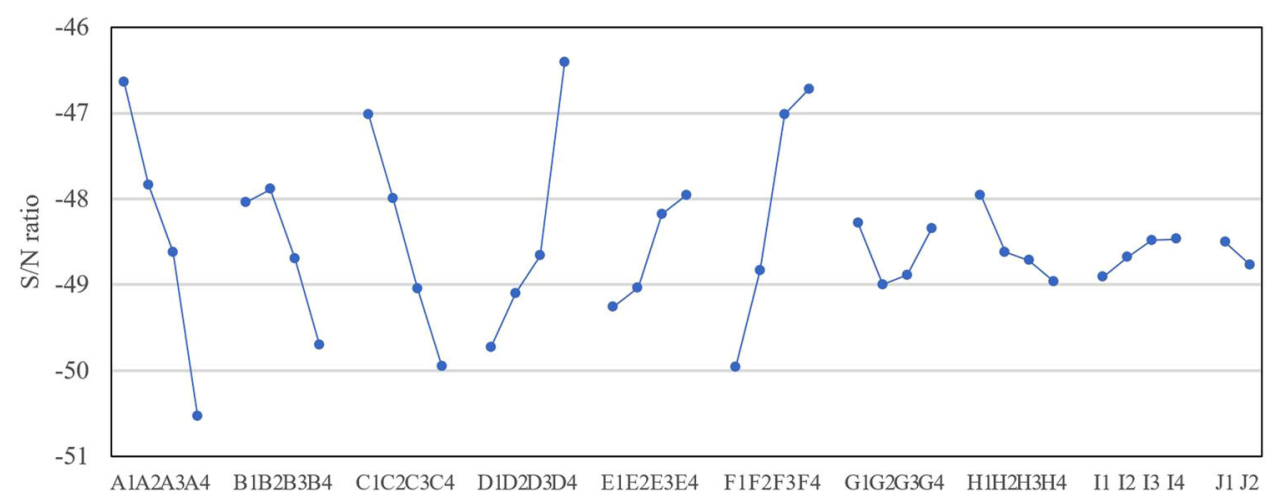

Fig. 3. $S / N$ ratios for the temperature at the cold end of the steel shell, with highest $S / N$ results for the case A1B2C1D4E4F4G1H1I3J1.

Table IV. Results based on analysis with the Taguchi method and standard main effect analysis

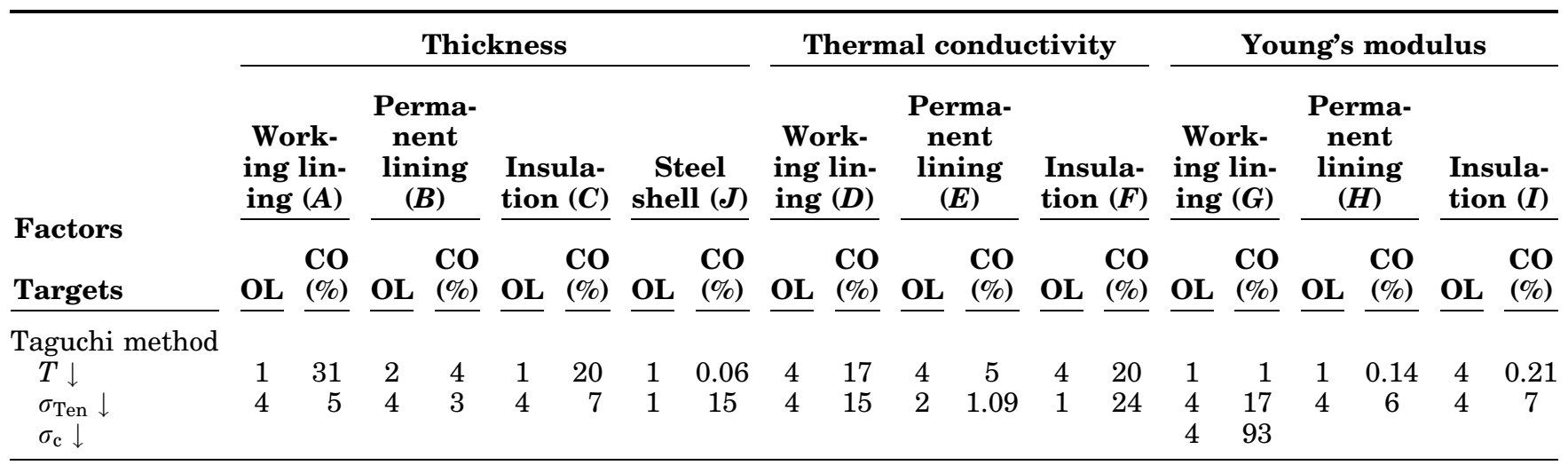

\begin{tabular}{|c|c|c|c|c|c|c|c|c|c|c|c|c|c|c|c|c|c|c|c|c|}
\hline Targets & OL & RK & $\mathbf{O L}$ & RK & OL & RK & OL & RK & OL & $\underline{\mathbf{R K}}$ & $\underline{\mathbf{O L}}$ & RK & OL & RK & OL & $\underline{\mathbf{R K}}$ & OL & RK & $\underline{\mathbf{O L}}$ & $\underline{\text { RK }}$ \\
\hline $\begin{array}{l}\text { Standard main } \\
\text { effect analysis }\end{array}$ & & & & & & & & & & & & & & & & & & & & \\
\hline$T \downarrow$ & 1 & 1 & 2 & 6 & 1 & 4 & 1 & 10 & 4 & 3 & 4 & 5 & 4 & 2 & 1 & 7 & 1 & 9 & 4 & \\
\hline $\begin{array}{l}\sigma_{\mathrm{Ten}} \downarrow \\
\sigma_{\mathrm{c}} \downarrow\end{array}$ & 4 & 8 & 4 & 9 & 4 & 7 & 1 & 4 & 4 & 3 & 2 & 10 & 1 & 1 & $\begin{array}{l}4 \\
4\end{array}$ & $\begin{array}{l}2 \\
1\end{array}$ & 4 & 6 & 4 & \\
\hline
\end{tabular}

$O L$ optimal level, $C O$ contribution, $R K$ ranking.

provides the significance ranks of impact factors by comparing the maximum difference of the mean values of response among levels of each factor. By comparing the results in Table IV, one can observe the different outcomes of the two methods. The main effect method with mean calculation provides qualitative results, whilst the Taguchi method offers quantitative values. Certain differences in optimal results between these two methods can also be identified. For instance, when one looks at the contributions to the temperature at the cold end of the steel shell, the Taguchi method indicated that the insulation thickness ranked second in importance, equal to the thermal conductivity of insulation, and the thermal conductivity of the working lining ranked fourth, while the main effect analysis indicated that the insulation thickness and the thermal conductivity of the working lining ranked fourth and third, respectively. Generally speaking, the Taguchi method is friendlier for decisionmaking.

\section{Proposal and validation of the optimal lining concept}

The final choice examined with the optimal lining concept takes into account the practical materials and the volume capacity of the steel ladle. The thermal conductivity and Young's modulus of material candidates for respective linings can be seen in "supplementary table SII". A compromise between the numerical results and practice has to be made. For instance, the insulation material candidate I4 is actually a fiber material and is unlikely to be widely 
Table V. Two proposed optimal lining concepts with different insulation materials

\begin{tabular}{|c|c|c|c|c|}
\hline & $\begin{array}{c}\text { Thickness } \\
\text { (mm) } \\
\end{array}$ & $\begin{array}{l}\text { Thermal conductivity } \\
\left(\mathbf{W} \mathbf{m}^{-1} \mathbf{K}^{-1}\right) \\
\end{array}$ & $\begin{array}{c}\text { Young's modulus } \\
\text { (GPa) }\end{array}$ & $\begin{array}{l}\text { Thermal expansion } \\
\text { coefficient }\left(10^{-6} K^{-1}\right)\end{array}$ \\
\hline Working lining (W1) & 155 & 9 & 40 & 12.0 \\
\hline Permanent lining (P4) & 52.5 & 2.2 & 45 & 5.0 \\
\hline Insulation (I2) (Case1) & 37.5 & 0.5 & 3 & 6.0 \\
\hline Insulation (I3) (Case2) & 37.5 & 0.38 & 4 & 5.6 \\
\hline Steel shell (S1) & 30 & 50 & 210 & 12.0 \\
\hline
\end{tabular}

used in the insulating lining, given its performance at high temperatures. A volume capacity decrease of the steel ladle is not desirable from an economical point of view. In the present study, the optimization of the lining concept was focused on the partial substitution of the permanent lining with the insulation lining. Thus, the thickness of the working lining and the total thickness of the permanent and insulation lining are the same as those of the reference case. The material with the highest thermal conductivity and lowest Young's modulus was proposed for the working lining. Since a moderate insulation effect is favorable for decreasing the steel shell temperature, while only slightly increasing the tensile stress in the steel shell, two insulation material candidates with lower thermal conductivities were proposed for the insulating lining. The details of lining structure and material properties are shown in Table V.

The thermal and thermomechanical behavior of the proposed lining concepts was studied with finite element modeling. The dimensionless temperature, tensile stress and compressive stress of the first proposed lining concept were $0.81,1.16$, and 0.74 , respectively. For the second proposed lining concept, the dimensionless values were $0.75,1.19$, and 0.75 (see "supplementary table SII"). The dimensionless values were calculated by dividing the actual values by those of the reference case. The comparison shows that the temperature at the cold end of the steel shell and the maximum compressive stress at the hot face of the working lining were decreased by $19 \%$ and $26 \%$ for case 1 and $25 \%$ and $25 \%$ for case 2 , respectively. For both cases, the maximum tensile stress at the steel shell slightly increased. In addition, case 2 showed a $6 \%$ lower steel shell temperature than case 1 , and a $0.3 \%$ higher tensile stress at the cold end of the steel shell.

\section{CONCLUSION}

The lining concept parameter study of a steel ladle using the FE method revealed the complicated effects of the lining structure and material properties on the thermal and thermomechanical responses. Using the Taguchi method, the optimal levels and significance of factors can be efficiently investigated. The statistical study using the Taguchi method facilitates decision making regarding the optimal lining concept. The proposed lining concepts show a significant decrease in temperature at the cold end of the steel shell and compressive stress at the hot face of the working lining, given the elastic material behavior of the refractories. The application of this methodology, while taking into account irreversible refractory material behavior, e.g., tensile failure, shear failure and creep, is of interest for future research.

\section{ACKNOWLEDGEMENTS}

Open access funding provided by Montanuniversitaet Leoben. The Competence Center for Excellent Technologies research programme in "Advanced Metallurgical and Environmental Process Development" (K1-MET) is supported by the Austrian Competence Centre Programme COMET (Competence Center for Excellent Technologies) with funds from the Federal Ministry for Transport, Innovation and Technology, the Federal Ministry of Economy, the provinces of Upper Austria and Styria, the Styrian Business Promotion Agency, and the Tyrolian Future Foundation.

\section{OPEN ACCESS}

This article is distributed under the terms of the Creative Commons Attribution 4.0 International License (http://creativecommons.org/licenses/by/4.0/), which permits unrestricted use, distribution, and reproduction in any medium, provided you give appropriate credit to the original author(s) and the source, provide a link to the Creative Commons license, and indicate if changes were made.

\section{ELECTRONIC SUPPLEMENTARY MATERIAL}

The online version of this article (https://doi.org/ 10.1007/s11837-018-3063-1) contains supplementary material, which is available to authorized users. 


\section{REFERENCES}

1. A. Ghosh, Secondary Steelmaking: Principles and Applications (Boca Raton: CRC Press, 2000), pp. 275-285.

2. A. Zimmer, A.N.C. Lima, R.M. Trommer, S.R. Braganca, and C.P. Bergmann, J. Iron. Steel Res. Int. 15, 11 (2008).

3. O. Volkova and D. Janke, ISIJ Int. 43, 1185 (2003).

4. C.E. Baukal Jr, Industrial Combustion Pollution and Control (New York: CRC Press, 2003), p. 567.

5. D. Gruber, T. Auer, H. Harmuth and J. Rotsch, in 2rd International Conference on Simulation and Modeling of Metal: Processes in Steelmaking, (Graz, Austria, 2007), pp. 291-296.

6. D. Gruber and H. Harmuth, Steel Res. Int. 79, 913 (2008).

7. D. Gruber and H. Harmuth, Steel Res. Int. 85, 512 (2014).

8. S. Jin, T. Auer, D. Gruber, H. Harmuth, M.H. Frechette, and Y. Li, Interceram 61, 37 (2012).

9. B. Cheng, P. Li, S. Tan, and Q. Zhao, J. Iron. Steel Res. Int. 27, 39 (2015).

10. L. Rebouillat, Y. Lee, G. Hodren and S. Kumar, in 14th Biennial Worldwide Congress: Unified International Technical Conference on Refractories, (Vienna, Austria, 2015), p. 466.

11. K. Andreev and H. Harmuth, in 3rd DIANA World Conference, (Tokyo, Japan, 2002), pp. 61-67.

12. G. Li, J. Liu, G. Jiang, and H. Liu, Adv. Mech. Eng. 7, 1 (2015).
13. S. Jin, D. Gruber, H. Harmuth, J. Soudier, P. Meunier, and H. Lemaistre, Int. J. Cast Metals Res. 27, 336 (2014).

14. S. Jin, H. Harmuth, and D. Gruber, Ironmak. Steelmak. (2017). https://doi.org/10.1080/03019233.2017. 1291153.

15. S. Jin, H. Harmuth, and D. Gruber, in 60th International Colloquium on Refractories, (Aachen, Germany, 2017), pp. 66-69.

16. R. Padmanabhan, M.C. Oliveria, J.L. Alves, and L.F. Menezes, Finite Elem. Anal. Des. 43, 1062 (2007).

17. S.K. Karna, R.V. Singh, and R. Sahai, in Proceedings of the National Conference on Trends and Advances in Mechanical Engineering, (Faridabad, Haryana, 2012).

18. A. Joshaghani, A.A. Ramezanianpour, O. Ataei, and A. Golroo, Constr. Build. Mater. 101, 317 (2015).

19. N.M. Ghazaly, M.M. Makrahy, K.R. Mahmoud, K.A. Abd, A. El-Gwwad, and A.M. Abd-El-Tawwab, Int. J Mech. Eng. 3, 1 (2013)

20. R.K. Roy, A Primer on the Taguchi Method, 2nd ed. (Dearborn: Society of Manufacturing Engineers, 2010), p. 261.

21. R.N. Kacher, E.S. Lagergren, and J.J. Filliben, J. Res. Natl. Inst. Stand. Technol. 96, 577 (1991).

22. D.C. Montgomery, Design and Analysis of Experiments, 8th ed. (Singapore: Wiley, 2013), p. 60. 